\title{
2082. Stress-strain response analysis and protective device design for buried pipeline impacted by perilous rock
}

\author{
Jie Zhang ${ }^{1}$, Zheng Liang ${ }^{2}$, Chengyu Xia ${ }^{3}$ \\ ${ }^{1,2}$ School of Mechatronic Engineering, Southwest Petroleum University, Chengdu 610500, China \\ ${ }^{3}$ School of Mechanical Engineering, Yangtze University, Jingzhou 434023, China \\ ${ }^{3}$ Corresponding author \\ E-mail: 1'longmenshao@163.com, ${ }^{2}$ liangz_2242@126.com,3411386996@qq.com
}

(Received 9 November 2015; received in revised form 25 January 2016; accepted 22 April 2016)

DOI http://dx.doi.org/10.21595/jve.2016.16626

\begin{abstract}
Collapse of perilous rocks is one of the most severe geological disasters for pipeline security. Stress-strain response of a buried pressure pipeline impacted by a perilous rock was simulated. Effects of impact velocity, rock's radius, pipeline's wall thickness, surrounding soil's elastic modulus and Poisson's ratio on stress, strain and deformation of the buried pipeline were investigated. The results show that the buried pipeline's upper part is prone to instability under the rock impact. Plastic area of the buried pipeline becomes from oval to bat type with the impact load increases. Strain of the impact dent center is a compressive strain, while it is a tensile strain on the two sides of the dent. High stress area, axial strain and plastic strain of the buried pipeline increase with the increasing of impact velocity and rock's radius, but they decrease with the increasing of wall thickness and soil's elasticity modulus. Surrounding soil's Poisson's ratio has a small effect on the stress and strain of the pipeline. Impact dent's size increases with the increasing of impact velocity and rock's radius. Dent depth decreases with the surrounding soil's elasticity modulus increases. With the wall thickness increases, impact dent depth first increases and then decreases. Finally, a protective device of buried pipeline is designed for preventing perilous rock impact. It can reduce the failure probability and improve the service life of buried pipeline for its simple structure and convenient installation.
\end{abstract}

Keywords: buried pressure pipeline, perilous rock, FEM, stress and strain, protective device.

\section{Introduction}

Long distance oil and gas pipelines across a vast area involving a variety of complex regions. Especially, there are many great potential safety hazards in the process when pipelines are in poor geological conditions and cross geological disasters areas. Geological hazards may cause the pipeline deformation, fracture and widespread destruction, then resulting in leakage of oil and gas, fire, explosion and other accidents [1]. Therefore, investigating disaster destruction and evaluation method of buried pipelines under the action of geological disasters, and formulating disaster prevention countermeasures have important significance to the oil and gas pipelines.

There are many typical disasters, such as collapse, floods, erosion, gully, landslide, mud-rock flow, fault and ground subsidence. Collapse of perilous rocks is one of the most severe geological disasters for pipeline security. The main hazard of perilous rock impact is the impact load. Especially in the areas with a bigger elevation difference, strong instantaneous wallop and additional force are produced when the perilous rock impacting the backfill soil. It may cause the stress of the buried pipeline exceeds the allowable stress, thus lead to pipeline deformation and rupture. For example, pipeline concrete cover plate was punctured by a perilous rock with $350 \mathrm{~m}^{3}$ in Shunxi in 2005. And a dent which is about $30 \mathrm{~cm}$ in diameter appeared in the pipeline [2]. Since Lan-Cheng-Yu Pipeline's operation in 2002, a number of events that perilous rock impact pipeline has occurred [3]. Wang [4] simulated the perilous rock movement by rock-fall software, and impact load of a buried pipeline was evaluated with two methods. Deng [5] simulated the dynamic response of buried pipeline induced by rock-fall impaction by 3DEC. Xiong [6] studied the influence law of certain factors on the safety of buried pipeline by LS-DYNA. But plastic 
deformation of the pipeline impacted by rockfalls were not considered in those studies.

In this paper, stress and strain of a buried pressure pipeline impacted by a perilous rock was simulated. Effects of impact velocity, rock's radius, wall thickness of pipeline, soil's elastic modulus and Poisson's ratio on stress, strain and deformation of the buried pipeline were investigated. A new protective device was designed for preventing perilous rock impact. Which can provide a theoretical foundation and basis for pipeline laying, safety evaluation and protection engineering.

\section{Cause analysis of perilous rocks}

Perilous rocks are results of the combined action of natural and human activities. Forming reasons of perilous rocks can be summed up in the following respects [7].

1) Terrain. Steep slope is the basic condition for perilous rocks. If the slope gradient is greater than $40^{\circ}$, perilous rocks appear easy. Cliffs is another way of rock fall off. There are 96 positions of perilous rocks in section from Zhang Jiagou to Shuang He along Zhong-Wu gas pipeline in China [8]. Where, $96.74 \%$ of collapsed perilous rocks appear in the slope with a slope gradient is greater than $40^{\circ}$, and $25 \%$ of perilous rocks are in the $50^{\circ}-55^{\circ}$ slope.

2) Rock property. Block or layered rocks caused by joint development or crushing of rock mass are the main sources of perilous rocks. Hard rock is more likely to fall off from the surface of soft rock [8].

3) Geologic tectonism. Various geological tectonism can destroy original complete strata in different degrees, and cut the intact rock into broken bodies with different sizes and forms. Which provides the necessary material base for perilous rocks.

4) Rainfall. In heavy rain or long after the rain [9], water seeps into the rocks along the fissures. It not only reduces the cohesion and friction of rock fracture, but also increases the quality of the rock mass [10].

5) Earthquake. The earthquake may loosen rock, then cause massive perilous rocks. For perilous rock in an instable state or critical equilibrium state, even small earthquake force might cause the destruction.

6) Human factors. Geological environment is transformed more and more intense by human engineering activities. Such as increasing load in the upper slope, cutting the lower slope, large blasting, slope excavation and so on.

\section{Numerical simulation model}

Deformation of the buried pipeline under the impact of perilous rocks is a nonlinear problem. The impact force is not uniform, and the soil-pipeline interaction is an important factor for pipeline's buckling behavior. In addition, pipeline is a thin shell structure, when the large deformation appears on the pipeline cross section, superposition principle can't be used. Therefore, it is difficult to solve the pipeline response by the analytic method, and the finite element method is more suitable [11]. Due to the shapes of perilous rocks are strange, there may be many sharp corners for the rocks. Backfill soil is the buffer medium between the rocks and the pipeline, then the rocks will not contact with the pipeline. Therefore, effects of small sharp corners on the pipeline deformation can be neglected. Effect of a rock with serious corners on the pipeline deformation will be studied in the future. Consequently, the perilous rock is assumed to be a ball-shape in this paper.

As shown in Fig. 1, four-node reduced integration shell elements are used for modelling the pipeline. Eight-node solid elements are employed for modelling the backfill soil, stratum and perilous rock. Pipeline's diameter is $813 \mathrm{~mm}$, the wall thickness is $8 \mathrm{~mm}$, and the perilous rock's radius is $0.86 \mathrm{~m}$. In order to eliminate the edge effect, size of the stratum is $10 \mathrm{~m} \times 7.5 \mathrm{~m} \times 15 \mathrm{~m}$. The thickness of backfill soil is $1 \mathrm{~m}$.

A linear isotropic strain hardening model has been considered in the plasticity model of the 
steel pipeline material. Numerical results are obtained for X65 steel pipeline, the yield stress is 448.5 MPa [12], Young's modulus is $206 \mathrm{GPa}$, Poisson's ratio is 0.3 , and density is $7800 \mathrm{~kg} / \mathrm{m}^{3}$. Mechanical behaviors of stratum and rock materials are described through an elastic-perfectly plastic Mohr-Coulomb constitutive model [12]. Materials of backfill soil and stratum are the same. The cohesion is $15 \mathrm{kPa}$, friction angle is $15^{\circ}$, elastic modulus is $20 \mathrm{MPa}$, density is $1840 \mathrm{~kg} / \mathrm{m}^{3}$, and Poisson's ratio is 0.3. Material of perilous rock is limestone, the cohesion is $6.72 \mathrm{MPa}$, friction angle is $42^{\circ}$, elastic modulus is $28.5 \mathrm{GPa}$, density is $2090 \mathrm{~kg} / \mathrm{m}^{3}$, and Poisson's ratio is 0.29 . Dilation angle of soil and rock is assumed equal to zero for cases in this paper.

A contact algorithm with a friction coefficient equal to 0.5 is employed to simulate the interactions between the pipeline outer surface and the surrounding soil [11]. A contact algorithm based on contact pairs is defined between the pipeline and backfill soil, and also between the backfill soil and perilous rock. Bottom surface of stratum is fixed. Gravity loading is applied to the whole model firstly. Internal pressure $2 \mathrm{MPa}$ is applied to the inner wall of buried pipeline. Initial impact velocity is applied to perilous rock.

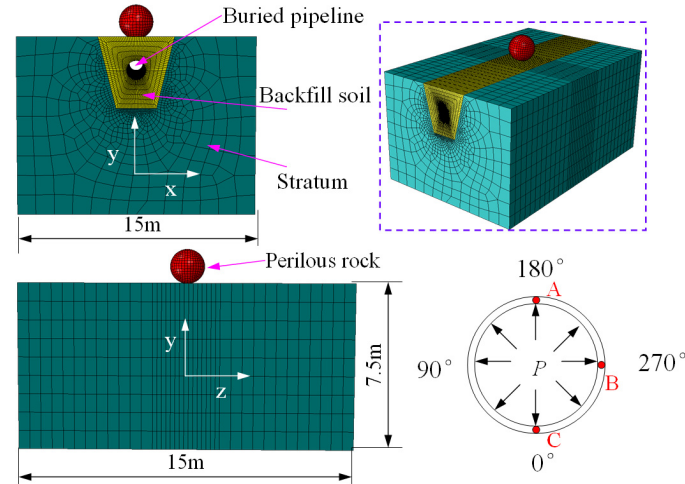

Fig. 1. Finite element models

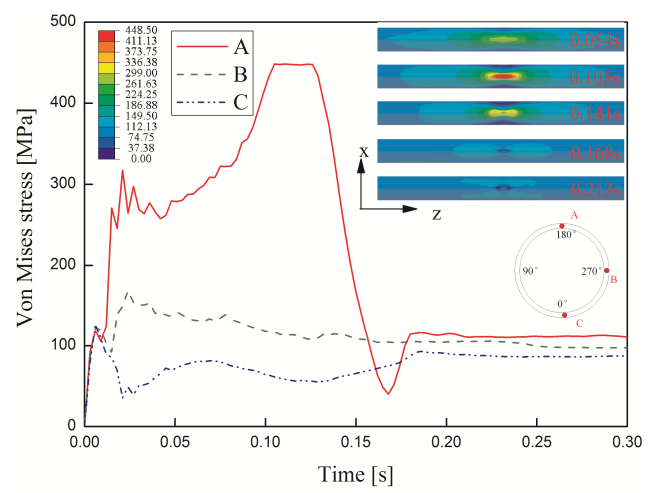

Fig. 2. Von Mises stress change curve in the impact process

\section{Simulation results and discussions}

\subsection{Von Mises stress}

The calculation time is $0.3 \mathrm{~s}$, von Mises stress distribution of the buried pipeline at different times and stress change curves of three points are shown in Fig. 2. Stress changes seriously before $0.18 \mathrm{~s}$. Stress of point A is the biggest in the impact process, while stress of point $\mathrm{C}$ is the smallest. So, the upper part of the buried pipeline is prone to instability under the impact of perilous rock. Before $0.105 \mathrm{~s}$, high stress distribution is oval, and it increases over time. In $0.105 \mathrm{~s}$, stress reaches the maximum value, and keeps 0.02 seconds. Then it decreases until $0.168 \mathrm{~s}$, stress of the center in the middle part of the pipeline is smaller than around. Because an impact dent has formed after plastic deformation, and the stress of impact dent is smaller. Stress amplitude fluctuation is small after $0.18 \mathrm{~s}$ for the resistance of the surrounding soil.

In order to study the effect of impact velocity, rock's radius, pipeline's wall thickness, elastic modulus and Poisson's ratio of surrounding soil on stress and strain of the buried pipeline. Impact process of perilous rocks were simulated in different conditions, and von Mises stress distributions of the buried pipeline are shown in Fig. 3. In Fig. 3(a), when impact velocity of perilous rock is smaller than $15 \mathrm{~m} / \mathrm{s}$, the stress is very small. High stress area of buried pipeline increases with the impact velocity increases. Two low stress areas appear on the end along the axial direction, and their sizes increase. There are some low stress areas with small size in the internal of high stress area for the impact dent. Therefore, high impact velocity has a greater destructive force to buried pipeline security. 
Radius of perilous rock affects its impulse and impact force. Stresses of the buried pipeline under impact of a perilous rock with different radius are shown in Fig. 3(b). High stress areas increase with the perilous rock's radius increases. When the radius is $0.7 \mathrm{~m}$, the stress is very small and its shape is oval. In Fig. 3(c), in the no-impact position, the stress caused by internal pressure decreases with the wall thickness increases. The maximum stress and high stress area decrease with wall thickness increases. It means that buried the pipeline with a bigger wall thickness is more secure under the impact of perilous rocks.

Backfill soil is the medium of buried pipeline and perilous rock, and its physical properties influence the pipeline's mechanical behavior. In Fig. 3(d), high stress area decreases with the soil's elasticity modulus increases, but its change rate is small. In Fig. 3(e), the stress and its distribution are not affected by the soil's Poisson's ratio. Therefore, surrounding soil's physical properties has a small effect on the stress of the buried pipeline.

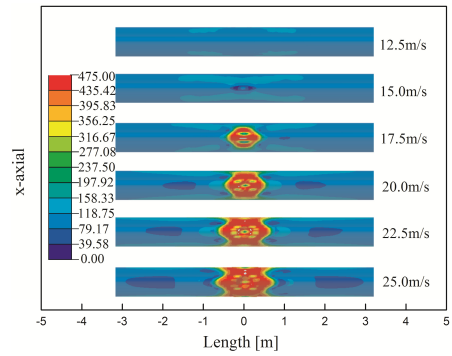

a) Impact velocity

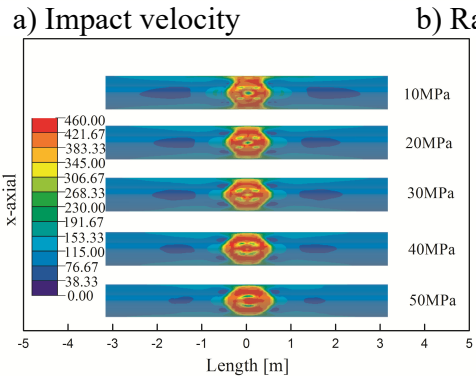

d) Elasticity modulus of surrounding soil

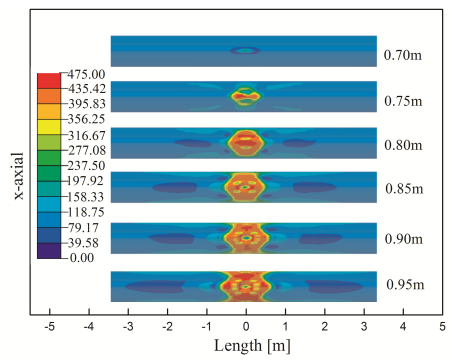

b) Radius of perilous rock

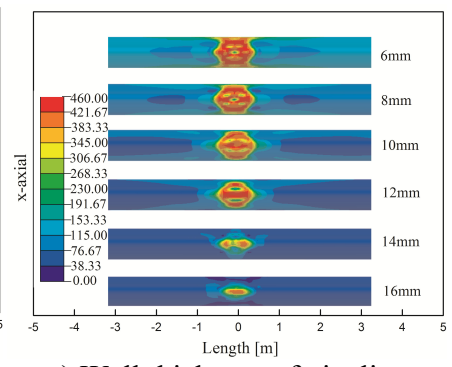

c) Wall thickness of pipeline

Fig. 3. Von Mises stress distribution in different conditions

\subsection{Axial strain}

The maximum axial strain and its distribution of the buried pipeline in different conditions are shown in Fig. 4. In the process of impacting, top part of the buried pipeline is compressed first and then an impact dent appears. Strain of the impact dent center is a compressive strain, while it is a tensile strain on the two sides of the impact dent. As shown in Fig. 4(a), compressive strain appears on the upper part of the buried pipeline without tensile strain when $V=12.5 \mathrm{~m} / \mathrm{s}$. With the increasing of impact velocity, tensile and compressive axial strain increase gradually, and the compressive axial is bigger than the tensile strain. The axial strain distribution becomes from oval to two half rings.

In Fig. 4(b), there is no tensile strain when the rock's radius is $0.7 \mathrm{~m}$, and the compressive strain is very small with an oval shape. Tensile and compressive axial strains increase gradually with the perilous rock's radius increases. But the change rules are non-linear. When the perilous rock's radius is smaller than $0.85 \mathrm{~m}$, the compressive strain is smaller. While the tensile strain changes are more even. In Fig. 4(c), axial strain decreases with the wall thickness increases. When the wall thickness is smaller than $12 \mathrm{~mm}$, the maximum strain is bigger, but the change rate is small. The maximum strain is smaller when the wall thickness is bigger than $12 \mathrm{~mm}$.

In Fig. 4(d), the maximum tensile and compressive axial strain decrease with the surrounding 
soil's elasticity modulus increases, but the change rate increases. In Fig. 4(e), axial strain distributions of buried pipeline are similar under different surrounding soil's Poisson's ratios. Axial strain decreases first and then increase with the Poisson's ratio increases, but the variation is small. Axial strain reaches the minimum value when Poisson's ratio is 0.25 .

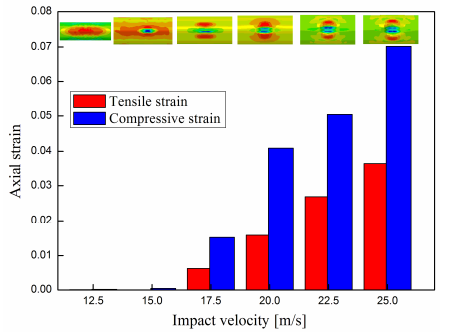

a) Impact velocity

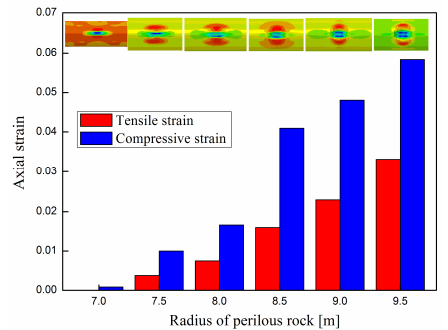

b) Radius of perilous rock

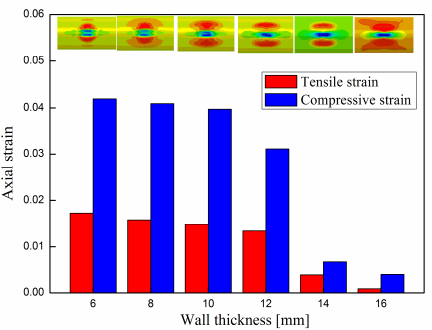

c) Wall thickness of pipeline

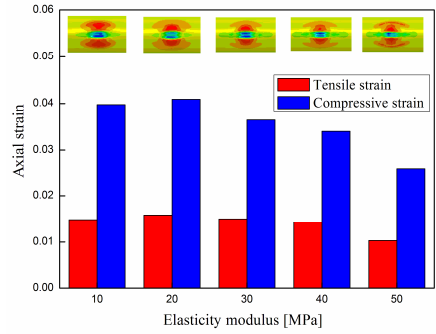

d) Elasticity modulus of surrounding soil

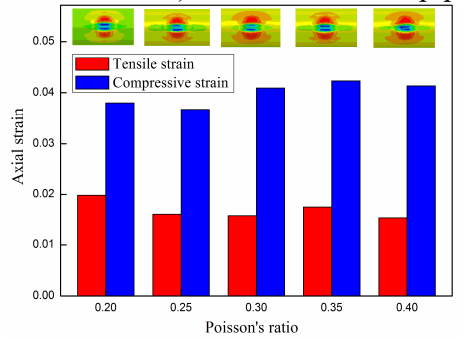

e) Poisson's ratio of surrounding soil

Fig. 4. Axial strain of buried pipeline in different conditions

\subsection{Plastic strain}

Fig. 5 shows the maximum plastic strain and its distribution of the buried pipeline in different conditions. In Fig. 5(a), there is no plastic strain when impact velocity is $12.5 \mathrm{~m} / \mathrm{s}$. Plastic area of the buried pipeline becomes from oval to bat type with the impact velocity increases, and the plastic strain also increases. The plastic strain is very small when impact velocity is smaller than $17.5 \mathrm{~m} / \mathrm{s}$. In Fig. 5(b), when the perilous rock's radius is $0.7 \mathrm{~m}$, the plastic strain is small for there is no impact dent. But with the rock's radius increases, the maximum plastic strain and plastic area increase gradually. In Fig. 5(c), plastic area and the maximum plastic strain decrease with the wall thickness increases. When the wall thickness is in $8 \mathrm{~mm}-12 \mathrm{~mm}$, the maximum plastic strain has a very small change. Therefore, the maximum plastic strain is very small before impact dent appears. Impact defects greatly enhance the instability of buried pressure pipeline.

In Fig. 5(d), the maximum plastic strain and plastic area decrease with the surrounding soil's elasticity modulus increases. Buried pressure pipeline is prone to failure in the soil with a smaller elasticity modulus. In Fig. 5(e), plastic strain and plastic area have a small change under the stratum with different Poisson's ratios.

\subsection{Deformation of cross section}

Fig. 6 shows vertical deformation of the buried pipeline's cross section. The deformation process can be divided into four stages. The first one is $0-0.024 \mathrm{~s}$, oval cross section appears under the impact load, there is only elastic deformation. The second stage is $0.024 \mathrm{~s}-0.048 \mathrm{~s}$, the pipeline begins to sink, a part of elastic deformation recovers. So the vertical deformation decreases along with the time. The third stage is $0.048-0.0114 \mathrm{~s}$, a bent appears on the pipeline under the impact load, and the vertical deformation increases sharply. The fourth stage is $0.114-0.189 \mathrm{~s}$, elastic deformation recovers, and there is only plastic strain.

Fig. 7 shows the relative displacement of the buried pipeline along $y$-axial direction in 
different conditions. It is assumed that the displacement of point $\mathrm{C}$ is zero. Displacement of the pipeline along $x, z$ direction is small. The relative displacement of the intermediate cross section along $y$-axial direction can reflect the deformation of the buried pipeline. In Fig. 7(a), the relative displacement of point $\mathrm{A}$ is the biggest under the impact of perilous rock. The peak displacement reflects the shape of impact dent. When impact velocity is less than $15 \mathrm{~m} / \mathrm{s}$, there is no impact dent. Impact dent appears and its size increases with the impact velocity increases. Impact dent will greatly reduce the bearing capacity of the buried pipeline and affect the pigging. Therefore, the impact dent should be avoided.

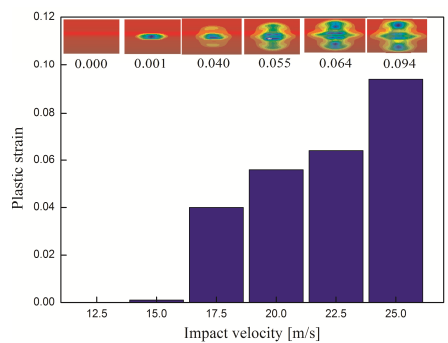

a) Impact velocity

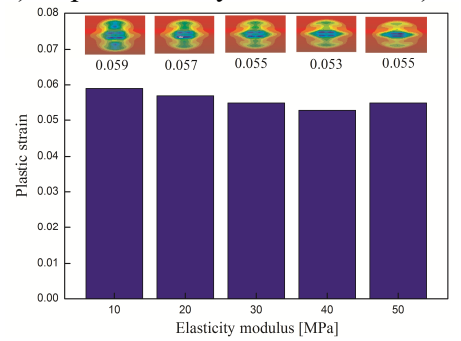

d) Elasticity modulus of surrounding soil

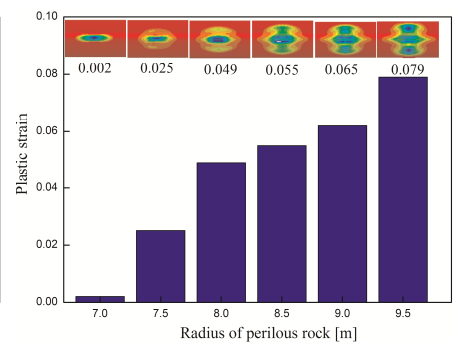

b) Radius of perilous rock

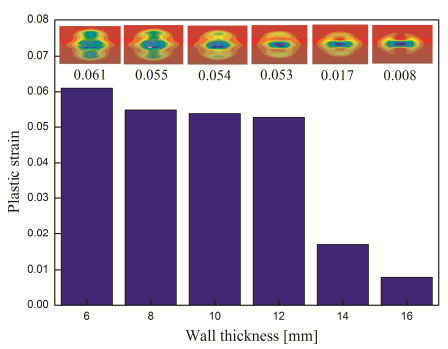

c) Wall thickness of pipeline

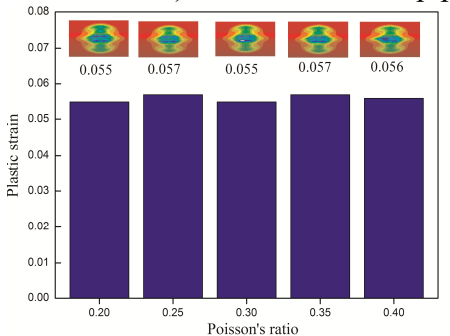

e) Poisson's ratio of surrounding soil

Fig. 5. Plastic strain distribution in different conditions

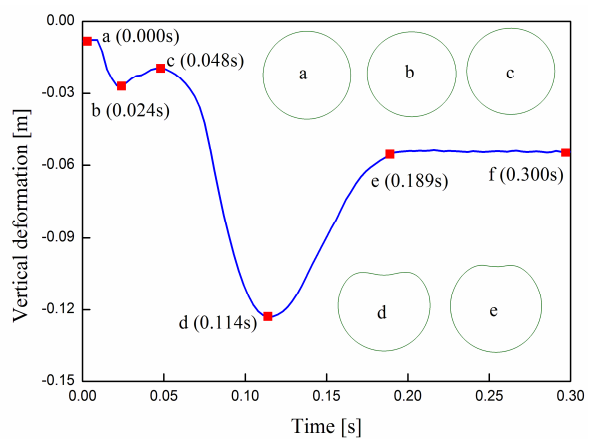

Fig. 6. Vertical deformation of the cross section

In Fig. 7(b), there is no impact dent when the perilous rock's radius is $0.7 \mathrm{~m}$. With the perilous rock's radius increases, impact dent width and depth increase with a nonlinear rule. Therefore, perilous rocks with a bigger volume should be cleared along the oil and gas pipelines. Damage of buried pipeline is very large if it is impacted by perilous rocks with a bigger volume. In Fig. 7(c), the relative displacement of the intermediate cross section is small when the pipeline's wall thickness is more than $12 \mathrm{~mm}$. Impact dent depth first increases and then decreases with the wall thickness increases. When the wall thicknesses are $8 \mathrm{~mm}$ and $10 \mathrm{~mm}$, deformations of the buried pipeline are similar. But the settlements of the whole pipeline are different. Settlement of the whole pipeline decreases with the wall thickness increases. Therefore, buried pipeline with a small wall thickness is prone to be bent under the impact load. 
In Fig. 7(d), impact dent depth and its change rate decrease with the surrounding soil's elasticity modulus increases. Therefore, backfill soil with a bigger elasticity modulus could slow down the deformation of the buried pipeline. In Fig. 7(e), the relative displacement of the buried pipeline is not affected by the surrounding soil's Poisson's ratio.

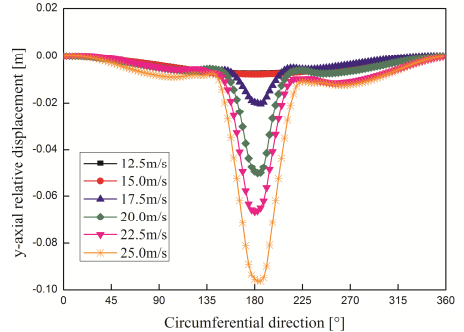

a) Impact velocity

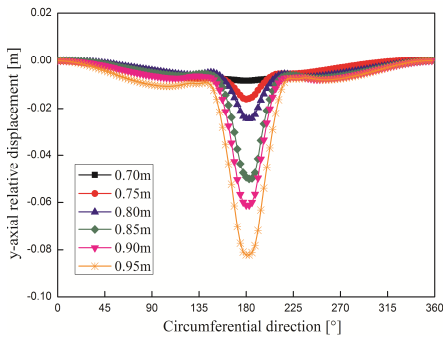

b) Radius of perilous rock

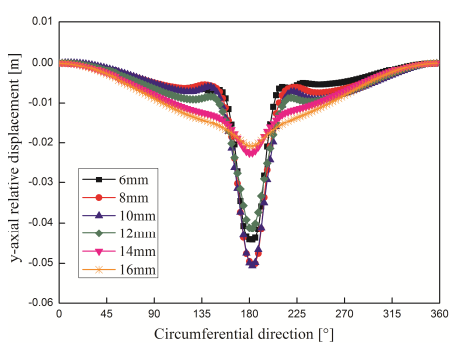

c) Wall thickness of pipeline

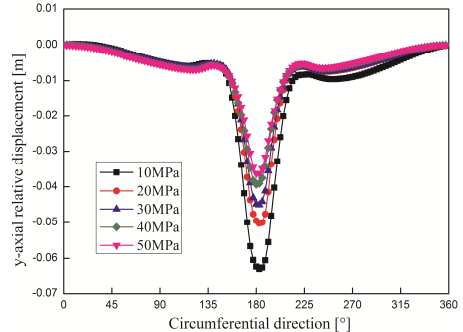

d) Elasticity modulus of surrounding soil

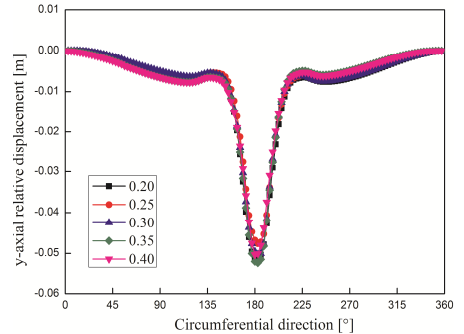

e) Poisson's ratio of surrounding soil

Fig. 7. $Y$-axial relative displacement of cross section in different conditions

\section{Protective measures design}

In order to reduce the failure probability and improve the service life of buried pipelines, protective measures should be designed [13]. Generally, protective measures of buried pipelines can be divided into two types. The first one is an active defense method, its basic idea is to enhance the stability of perilous rock, and prevent avalanching of perilous rocks. Such as supporting, anchor, inlaying rock cavity, grouting, drainage engineering and so on. The second one is a passive defense method, its basic idea is to avoid damaging buried pipeline after perilous rock collapse. For example, stopper dam, fence, safe net system, rock slot, avoid belt, stone grooming, shed hole and other structures. In the practical engineering, active defense methods and passive defense methods are used by combination.

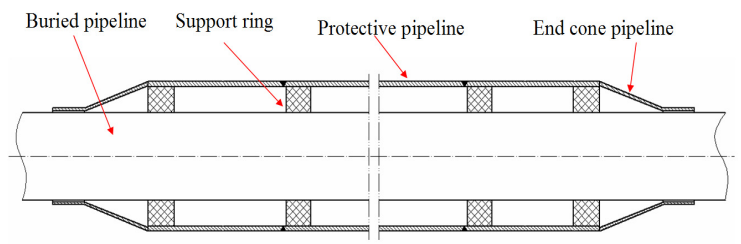

Fig. 8. Protective device of the buried pipeline

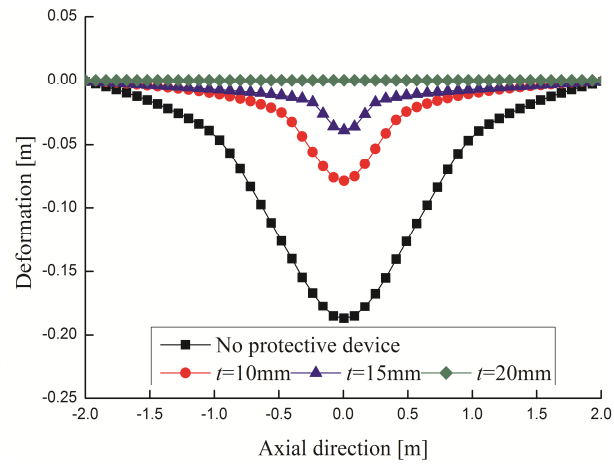

Fig. 9. Pipeline's deformation with and without a device

In this paper, a protective device of buried pipelines is designed for preventing perilous rocks 
impact as shown in Fig. 8. It consists of buried pipeline, support ring, protective pipeline and end cone pipeline. For geological disaster area, a protective pipeline is sleeved on the buried pipeline. Support rings are evenly distributed in annulus between protective pipeline and buried pipeline. The support rings can be made by rubber, PTFE or other plastic materials. Cone pipelines were installed in the end. After perilous rocks impacted, deformation appears on protective pipeline firstly, and annulus hindered the contact between protective pipeline and buried pipeline. If the buckling appears on protective pipeline, it can be timely repaired and replaced without stopping the transmission of oil and gas. Therefore, this protective device can effectively protect oil and gas pipeline, and be widely used in different locations for its simple structure and convenient installation.

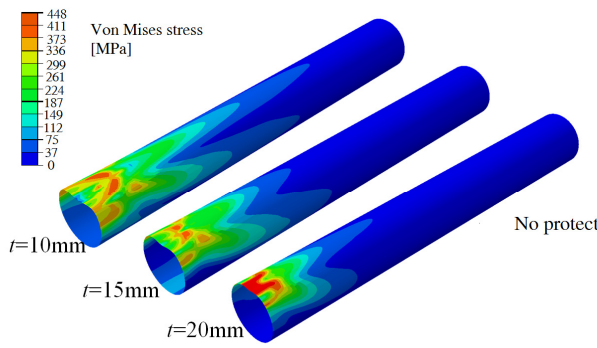

(a) Protective pipeline

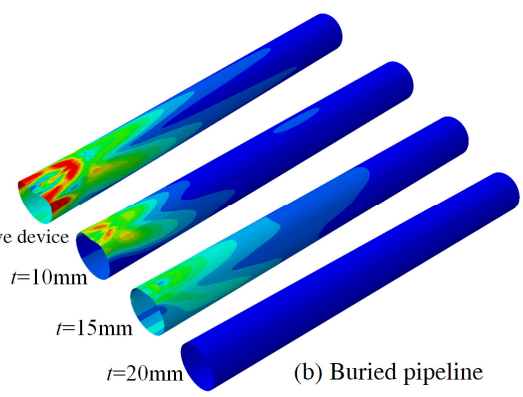

(b) Buried pipeline

Fig. 10. Von Mises stress distribution of the protective pipeline and buried pipeline

When the perilous rock's radius is $0.86 \mathrm{~m}$, the impact velocity is $20 \mathrm{~m} / \mathrm{s}$, pipeline diameter is $813 \mathrm{~mm}$, pipeline wall thickness is $8 \mathrm{~mm}$, the deformation process of the buried pipeline with a protective pipeline was simulated. Fig. 9 shows the deformation of the buried pipeline under the protection of the protective pipeline with different wall thicknesses. Deformation of the buried pipeline without the protective device is the most serious. Under the protection of the new device, deformation of the buried pipeline decreases obviously. Dent depth of the pipeline decreases with the protective pipeline's wall thickness increases. When the protective pipeline's wall thickness is $20 \mathrm{~mm}$, there is no deformation for the protective pipeline is no contact with the buried pipeline under rock's impact action.

Fig. 10 shows the von Mises stress distribution of the two pipelines. High stress area of the protective pipeline increases with its wall thickness decreases. High stress area of the buried pipeline without protective device is the greatest. Stress of the buried pipeline decreases with the protective pipeline's wall thickness increases. It is zero when the protective pipeline's wall thickness is $20 \mathrm{~mm}$. Therefore, the buried pipeline is safe in this condition.

\section{Conclusions}

1) Collapse of perilous rocks is one of the most severe geological disasters for pipeline security. Forming reasons of perilous rocks were summarized. In order to reduce the failure probability and improve the service life of buried pipelines, a protective device is designed for preventing perilous rock impact. It can effectively protect oil and gas pipeline for its simple structure and convenient installation.

2) According to numerical simulation of perilous rock impact buried pipeline, the pipeline's upper part is prone to instability. Stress amplitude fluctuation is small for the resistance of surrounding soil. High stress area of the pipeline increase with the increasing of impact velocity and perilous rock's radius, but it decreases with wall thickness increases. Surrounding soil's physical properties have a small effect on the stress of buried pipelines.

3 ) In the process of impacting, the pipeline's top part is compressed first and then an impact dent appears. Strain of the impact dent center is a compressive strain, while it is a ensile strain on the two sides. Axial strain of the pipeline increases with the increasing of impact velocity and 
rock's radius, but it decreases with the increasing of wall thickness and soil's elasticity modulus.

4) Plastic area of the buried pipeline becomes from oval to bat type with the impact velocity increases, and the plastic strain also increases. Plastic strain and plastic area increase gradually with the rock's radius increases. But they decrease with the increasing of wall thickness and soil's elasticity modulus.

5) Impact dent appears and its size increases with the increasing of impact velocity and rock's radius. Dent depth decreases with the increasing of the surrounding soil's elasticity modulus, but it is not affected by the soil's Poisson's ratio. Impact dent depth first increases and then decreases with the wall thickness increases.

\section{Acknowledgements}

This work was supported by Science and Technology Innovation Talent Engineering Project of Sichuan Province (2015097) and National Natural Science Foundation of China (51134004).

\section{References}

[1] Zhang J., Liang Z., Han C. J. Numerical simulation of buckling behavior of the buried steel pipeline under reverse fault displacement. Mechanical Sciences, Vol. 6, Issue 2, 2015, p. 203-210.

[2] Shi X. W., Deng Q. L., Dong G. L. The hazards of landslides and rockslides to pipeline. Oil and Gas Storage and Transportation, Vol. 32, Issue 3, 2013, p. 295-299.

[3] Li Y. B., Wang J. H., Zhang G. T. Analysis of the buried pipeline stress and deformation due to the impact load of landslide. Journal of Logistical Engineering University, Vol. 26, Issue 6, 2010, p. 31-35.

[4] Wang L., Deng Q. L., Yang H. J. Evaluation on the safety of natural gas pipeline impacted by dangerous rock fall. Hydrogeology and Engineering Geology, Vol. 51, Issue 5, 2007, p. 29-32.

[5] Deng X. J., Xue S. F., Tong X. H. Numerical simulation in response of buried pipeline induced by rock-fall transverse impaction. Journal of China University of Petroleum, Vol. 23, Issue 6, 2009, p. 111-115.

[6] Xiong J., Deng Q. L., Zhang H. L. Safety assessment on the response of buried pipeline caused by rockfall impact load. Safety and Environmental Engineering, Vol. 20, Issue 1, 2013, p. 108-114.

[7] Wang H., Yu Z. F. Quantitative analysis of rockfall impact on buried pipeline. Petroleum Engineering Construction, Vol. 35, Issue 6, 2009, p. 5-8.

[8] Xiang X. Research on Motion Characteristics and Impact Force of Rockfall. China University of Geosciences, Wuhan, 2010.

[9] Butler D., Oelfke J., Oelfke L. Historic rockfall avalanches, Northeastern Glacier National Park, Montana, USA. Mountain Research and Development, Vol. 6, Issue 3, 1986, p. 261-271.

[10] Chau K., Wong R., Liu J. Rockfall hazard analysis for Hong Kong based on rockfall inventory. Rock Mechanics and Rock Engineering, Vol. 36, Issue 5, 2003, p. 383-408.

[11] Zhang J., Liang Z., Han C. J. Buckling behavior analysis of buried gas pipeline under strike-slip fault displacement. Journal of Natural Gas Science and Engineering, Vol. 21, 2014, p. 921-928.

[12] Vazouras P., Karamanos S. A., Dakoulas P. Finite element analysis of buried steel pipelines under strike-slip fault displacement. Soil Dynamics and Earthquake Engineering, Vol. 30, Issue 11, 2010, p. 1361-1376.

[13] Zhang J., Liang Z., Han C. J. Numerical simulation of mechanical behavior of buried pipeline impacted by perilous rock. Mechanika, Vol. 21, Issue 4, 2015, p. 264-271.

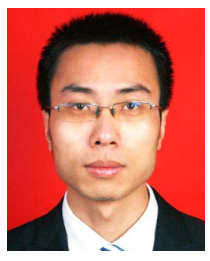

Jie Zhang is a lecturer in Southwest Petroleum University, Chengndu, China. His current research interests include pipeline mechanics and numerical simulation of oil and gas equipment. 

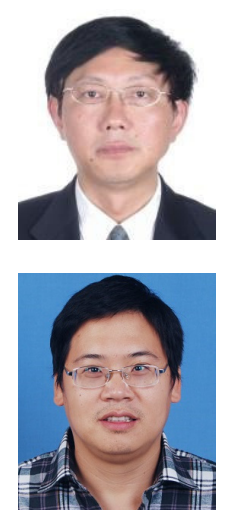

Zheng Liang is a Professor in Southwest Petroleum University, Chengndu, China. His current research interests include design and the theory of oil and gas equipment.

Chengyu Xia is an Associate Professor in Yangtze University, Jingzhou, China. His current research interests include pipe string mechanics and downhole tool. 